\title{
The Role of Organizational Culture in Job Satisfaction and Turnover: A Study of Pakistani Employees
}

http://doi.org/10.21272/bel.4(1).106-112.2020

Ansar Abbas, ORCID: https://orcid.org/0000-0002-2939-2613

MPhil, Scholar, Department of Business Administration, Ghazi University, DG.Khan, Pakistan

Roman Khan, ORCID: https://orcid.org/0000-0003-0366-5369

Lecturer, Faculty of Management Sciences, Abasyn University, Islamabad, Pakistan

Fizza Ishaq, ORCID: https://orcid.org/0000-0003-3028-8263

Library Incharge, NUST Quetta Campus, Pakistan

Khalid Mehmood, ORCID: https://orcid.org/0000-0002-7494-7809

Lecturer, Faculty of Management Sciences, Ghazi University, DG.Khan, Pakistan

\begin{abstract}
The human capital becomes a significant achievement of every organization in the context of the transformation of the fundamental principles in doing business. Every business structure creates and maintains a unique organizational culture that determines the degree of comfortable conditions for employees in their workplace, the level of their interest in the successful operation of the company and the desire to gain leadership in the market. The human resources and the degree of workers' satisfaction with jobs directly affect the performance of the company. At the same time, the organizational culture of the company depends on the general policy of the company in which the maximization of profit, not the employee's satisfaction with working conditions, is the primary purpose of its activity. The systematization of existing scientific capacity in the field of human resources management has shown the relationship between the level of dissatisfaction of employees with working conditions and the degree of their readiness to find a new place where they can work in more comfortable conditions. The study is based on the use of analytical and comparative methods. The object of the research includes organizations in Muzaffargarh, Layyah and Dera Ghazi Khan Punjab (Pakistan). The study is based on a method of data collection, which contains the analysis of the results of 320 successfully returned (out of 350 distributed) questionnaires. A 5-digit Likert scale analyzed the results. The purpose of the research is to analyze the relationship between job satisfaction, organizational culture and staff turnover in Pakistan. According to the results of the study, the authors conclude that organizational culture directly influences employee satisfaction, which in its turn has a negative impact on employee turnover. The results of the conducted research can be useful for managers and business owners in terms of understanding the possibilities of improving the employees' productivity from the perspective of increasing their satisfaction with working conditions.
\end{abstract}

Keywords: Human Resource Management, Job Satisfaction, Organizational Culture, Turnover.

JEL Classifications: J28, M14, E24, J63.

This work is licensed under a Creative Commons Attribution 4.0 International License

Cite as: Abbas, A., Khan, R., Ishaq, F., Mehmood, K. (2020). The Role of Organizational Culture in Job Satisfaction and Turnover: A Study of Pakistani Employees. Business Ethics and Leadership, 4(1), 106-112. http://doi.org/10.21272/bel.4(1).106-112.2020.

(C) The Authors, 2020. This article is published with open access at Sumy State University.

\section{Introduction}

In recent years a trend starts in Pakistani employees to switch from one organization to another for the sake of comfort workplace and other benefits. They are trying to find satisfaction where they apply their skills independently and have autonomy with self-affinity. As human resources are capitals of an organization. A company needs to set up an organizational culture for keeping its position in the market which is highly competitive. According to Raziqa and Maulabakhsha (2015), workers are the essential part of an organization for attaining the vision and mission of the company, where workers must fulfill the traditional standard of company for assuring their work quality. For accomplishing the standards, the workers require an environment where they can work freely without any obstacles. The organizational culture should be established that might 
give us constant to a company and bring constant up gradations. The culture of a company plays a significant role in the development of a company since, it not only affects worker's satisfaction but also their retention. In the modern world, because of the dynamic nature of the environment, the business is going through numerous challenges like satisfaction of workers for dealing with varying and growing environment and also to attain success and endure in the competitive market. For enhancing the job commitment, effectiveness, efficiency, and growth, the organizations should provide better work conditions that cause satisfaction (Raziqa and Maulabakhsha, 2014). If the culture of an organization is elastic, it drives to grand such workplace atmosphere to workforces where they could work without difficulty and without feeling any burden which resultantly surge the satisfaction level of employees. Job satisfaction is an important essential element for workers' motivation and inspiration for their better performance (Vroom, 1964).

The organizational culture is a very essential technique for encouragement and discouragement of worker`s behaviors in the company. And the culture of the company can be affected through beliefs, attitudes and norms that centrals to strong communication among the workers (Huang et al., 2015). Job satisfaction is very important and the main reason for retaining and attracting skilled workers in the organization. Moreover, the present scholarly believes that there is a positive relationship between worker`s satisfaction and organizational culture (Harter et al., 2002; Huang et al., 2015; Symitsi, Stamolampros \& Daskalakis, 2018).

\section{Literature Review}

\subsection{Organizational Culture}

The positive workplace environment and employee's satisfaction can be created by structuring a positive workplace environment in which associates have optimistic interactions and get tasks in a way which aids them to achieve organizational goals and highly personal satisfaction (Meterko et al., 2004; Mulcahy and Betts, 2005). The beliefs, attitudes and values of workers are the strongest elements of the word "organizational culture", because the organizational culture is made through people (Hartnell \& Kinicki, 2011); moreover they explained that an organization's cultural standards sturdily affects all who are intricate in the organization. Mostly those standards are imperceptible but are essential to understand and improve the performance. The meaning and limitations of organizational culture are frequently disordered. Certainly, the idea has been illustrated as "a riddle wrapped in a mystery wrapped in an enigma" (Ogbonna \& Harris, 2008). The correct organizational culture is taken to be an important prerequisite for high levels of organizational outcomes, and it is valued for organizational analyses drives (Fey and Denison, 2003). Deal \& Kennedy (2002) recommended that "strong" shared values could boost organizational output and performance. He also declared that a 'strong' culture makes workers able to feel better regarding to what they work and fix, and they likely will work harder and harder. And according to Hartog \& Verburg (2004), the organization`s outcome is about the point where an employee achieves the mission of an organization inside the workplace. And in order to know about the organization`s outcome, the person has to understand and examine the culture of an organization (Denison, Haaland \& Goelzer, 2004). According to Fey and Denison (2003), in order to find organizational performance, the strength of organizational culture is an essential element. And moreover, he defined that the strength of organizational culture is an essential reason in measuring the organizational outcome. The organizations with a 'strong' culture have a well-defined value which provides aim to workers for embracing the culture (Cameron \& Quinn, 2006). The employees follow the culture as they accept as true that it is a right and important thing to be followed. The "strong" organizational culture was firstly abstracted like a clear set of, beliefs, practices, values and norms that are followed via the outmost number of followers within the organization (Alvesson, 2005) and he further explained that strong organizational culture consists of those factors augmented agreement around the strategic course. With the help of "strong" organizational culture, the employees get more attachment to their job and work assigned to them with high commitment and productivity. And at the same time, some organizations have a strong culture, and some have weak cultures. Alvesson (2005) declared that the performance of an organization depends upon the strengths and consistency of the organizational culture. The 'strong' organizational culture increase worker commitment and engagement (Schein, 2011).

\subsection{Job Satisfaction}

The importance of work environment and job satisfaction are getting a very high place in today's world due to its impact and nature for the present society. Denish suggests that an organization can boost its outcomes by upgrading and improving the internal climate of work`s environment that could have a positive effect on the organization's overall productivity (Buhai, Cottini \& Nielseny, 2008). Furthermore, Hoppok and Spielgler (1938) explained that job satisfaction is a cohesive set of psychological, physiological and ecological circumstances which motivates workers to confess that they are satisfied or else pleased with their works. If proper devotion is specified on supervision, interpersonal, and recognition of the employees then the level of job satisfaction can increase (Castillo \& Cano, 2004). 


\subsection{Turnover}

The turnover is a very serious problem for individual firms and organizations as due to turn over the organizations and firms lose their valuable staff and human capital who are highly qualified and skillful persons. According to Wahl \& Prause (2013), worldwide skill shortages have become a crucial issue for the most of organizations. And keeping this point of view that progress and success of organizations lie upon the human capital (Bhati and Manimala, 2011) for making organizational rentals and surging the growth of organization the talented workers are perceived as the main source and potential. By massive-restructuring and an economic slowdown the war for talented workers has been ongoing (Beechler \& Woodward, 2009).

\subsection{Conceptual Model and Hypothesis Statement}

In order to empirically test the impact of organizational culture on satisfaction and turnover, a conceptual model is developed premised on the reviewed empirical literature. In this conceptualized model, organizational culture is the predictor variable, while satisfaction and turnover are the outcome variables. Figure 1 depicts this conceptualized research model. The hypothesized relationships between the research constructs will be stated hereafter.

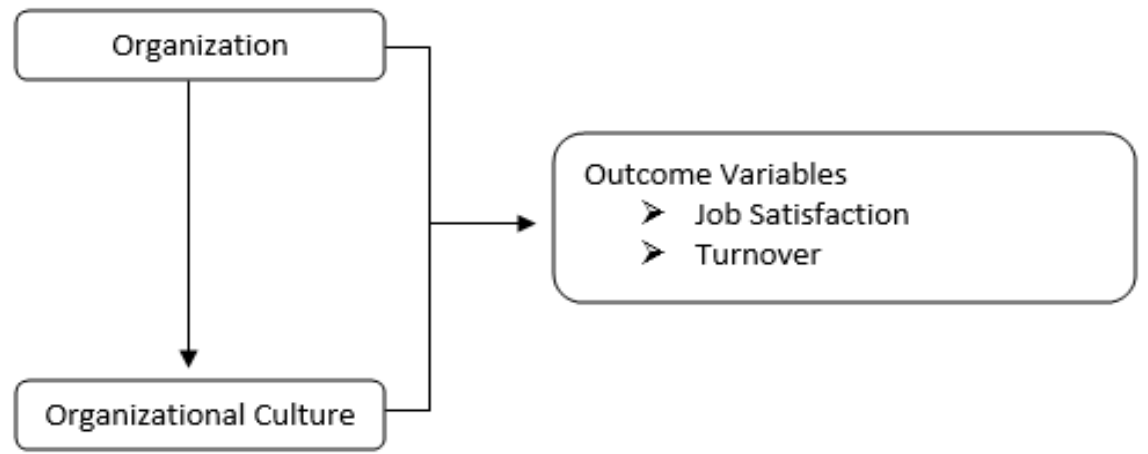

Source: Compiled by authors

Figure 1. Conceptual Model

\section{Hypothesis Statement}

H1. Organizational culture has a positive significant relationship with job satisfaction.

H2. Job satisfaction has a negative significant relationship with turnover.

H3. Organizational culture has a negative significant relationship with turnover.

\section{Methodology}

The study sample includes 320 employees working in different industry groups from three districts (Muzaffargarh, Layyah and DG.Khan) and focuses on participants who have received mentoring from senior employees. A questionnaire was developed and measured variables through 5 Likert Scale and distributed in the industry groups after we obtained permission from executives. The human resource departments provided the corresponding department lists and position information. In the investigation process, we adopted a multiple-period data-collection with a simple data collection method. The demographic information of respondents listed in a given table (Table 1).

Table 1. Demographic Characteristics

\begin{tabular}{|l|l|c|c|}
\hline \multicolumn{1}{|c|}{ Characteristics } & No & \% \\
\hline Gender & Male & 208 & 65 \\
\hline & Female & 112 & 35 \\
\hline & $25-29$ Years & 128 & 40 \\
\hline & $30-39$ Years & 96 & 30 \\
\hline Age & $40-49$ Years & 64 & 08 \\
\hline & $50-59$ Years & 26 & 02 \\
\hline & More than 60 Years & 06 & 50 \\
\hline & Banking & 160 & 30 \\
\hline Industry & Education & 96 & 15 \\
\hline & Chemicals & 48 & 01 \\
\hline & Textile & 03 & 04 \\
\hline Working Tenancy & Petroleum & 13 & 19 \\
\hline & Less than 1 Years & 62 & 39 \\
\hline & $1-5$ Years & 125 & 33 \\
\hline
\end{tabular}




\section{Data Analysis and Results}

For analyzing data, the SPSS software version 20 has been used. The participants of the research were taken as categorical variables. Job satisfaction, organizational culture and turnover intention were taken as continuous variables. Lastly, structural equation modeling was used to examine surveyed statistics that was constructed on a conceptual path model. For finding and testing the validity and reliability, the Cronbach's alpha (upper 0.70) for the internal consistency was applied. The survey questionnaire included measures of organizational culture, job satisfaction, turnover intention and demographic characteristic. Five-point Likert scale from $(1=$ strongly disagree, $2=$ disagree, $3=$ natural, $4=$ agree and $5=$ strongly agree $)$ aimed at all the items measurement, except demographic variables. The results suggest the constructs have a good indication of reliability, in which Cronbach's alpha differed from 0.803 to 0.932 .

Table 2. Correlation Matrix amongst entire study variables

\begin{tabular}{|l|c|c|c|c|c|}
\hline \multicolumn{1}{|c|}{ Variables } & Mean & SD & $\mathbf{1}$ & $\mathbf{2}$ & $\mathbf{3}$ \\
\hline 1. Organizational culture & 2.85 & .84 & $(.80)$ & & \\
\hline 2. Job satisfaction & 4.49 & 1.08 & $.556^{* *}$ & $(.87)$ & \\
\hline 3. Turnover & 3.09 & 1.01 & 758 & $-.572^{* *}$ & $(.93)$ \\
\hline
\end{tabular}

Note: Figures of coefficient alpha are in brackets.

Correlation was significant at the 0.05 level (2-tailed) and

** Correlation was signification at the 0.01 level (2-tailed).

Source: Compiled by authors

Table 2 displays the correlation amongst study variables. As illustrated job satisfaction $(\mathrm{r}=.556, \mathrm{p}<.01)$ significantly positively correlated with organizational culture. Turnover $(\mathrm{r}=-.572, \mathrm{p}<.01)$ negatively correlated by job satisfaction. This result shows the objective of the research.

\subsection{Relationship between organizational culture and job satisfaction}

The organizational culture shows a positive relation with job satisfaction. Job satisfaction continuously increasing with the organizational culture, the graph shows the increasing level of satisfaction with organizational culture. This shows that if the organization follows the principles \& ethics than it will achieve the employees' satisfaction. The satisfaction always leads to the performance of productivity and efficiency. The internal satisfaction and commitment of employees create loyalty for the firm.

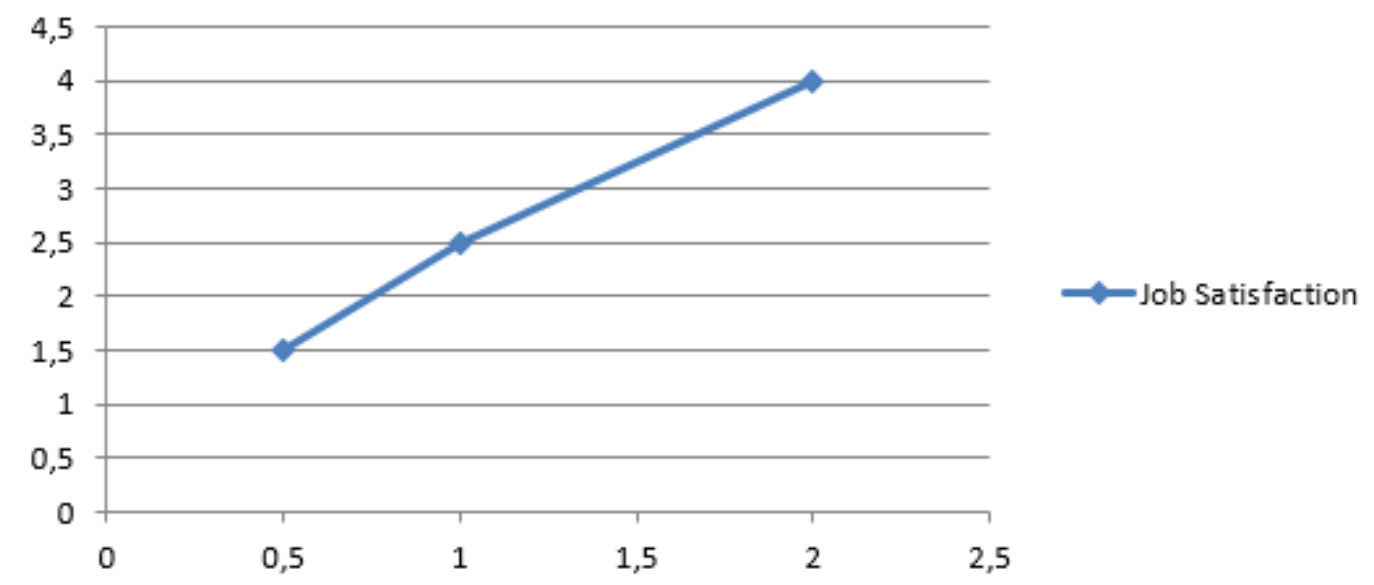

Figure 2. Organizational Culture

Source: This study

\subsection{Relationship between job satisfaction and turnover}

Job satisfaction shows a negative relation with turnover. In this graph job satisfaction at the level of 0.5 and turnover at the level of 0.2 mean that the satisfaction level increased but the turnover level decreased. This graph shows that when a firm properly implements its rules, regulations and creates working environment for its employees than the turnover rate will be minimum, and the productive rate will be maximum. 


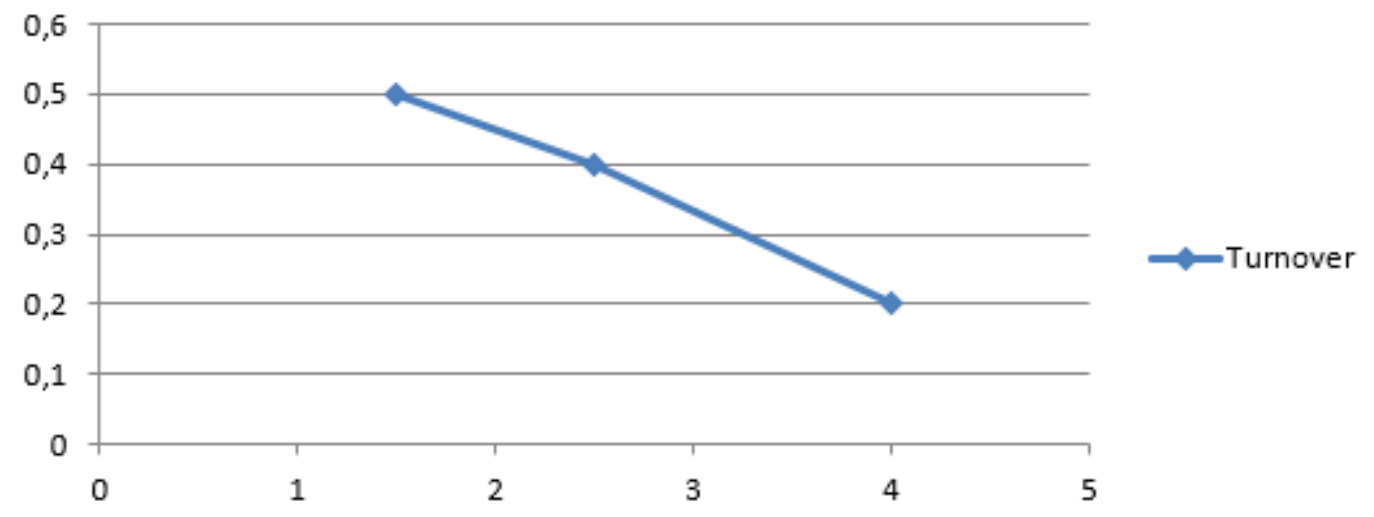

Figure 3. Satisfaction

Source: This study

\subsection{The relationship between organizational culture and turnover}

The organizational culture and turnover have a negative significant relation with each other. Both are compulsory for an organization. The firm can make specific rules and ethics for its operation.

The implementation of rules and regulations are the main source of good culture. The proper implementation of the roles and regulations in any organization increases the satisfaction level of employees and negatively impacts the turnover.

\section{Discussion}

The organizational culture starts with the establishment of the organization. It is a compulsory part of the organization. This graph shows the relation of organizational culture with satisfaction and turnover in quantitative values. The first stage shows that organizational culture is at the level of 3.2 than job satisfaction at 2.4 but turnover is at 2, this is the start of business. At the second stage, the OC is at 3.9 than JS at 2.8 but $\mathrm{TO}$ at 1.3, this stage belongs to where the business in his growth line. The third stage is a maturity stage where the satisfaction level is high with a strong organizational culture, but turnover is almost minimum at this level. Here the OC level is at 4.5 with $4.1 \mathrm{JS}$ and TO be at 0.8 . The fourth stage is the last one, where OC is going to decline and almost turnover starts to be increased. Therefore, the organization needs to adopt new culture and disciplines with the passage of time. Every organization continuously adopts new strategies and trends with a changing environment to stable its position in the market. The organizational culture almost affects the whole organization and its employees.

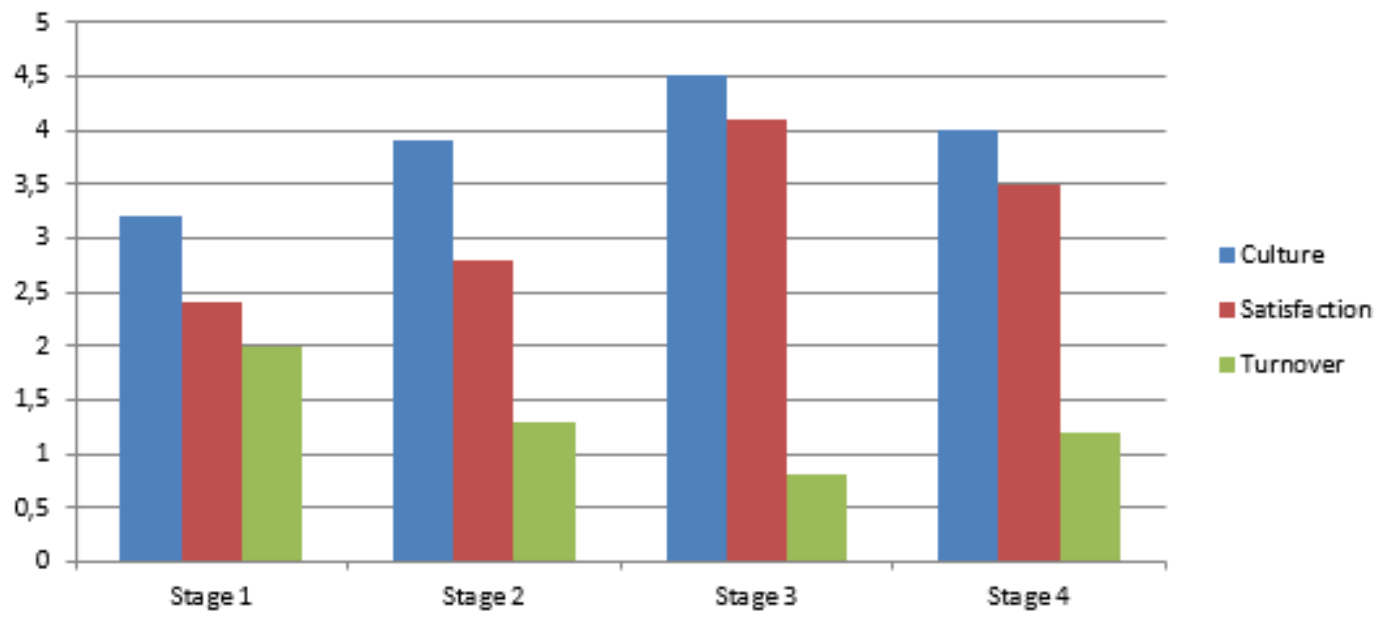

Figure 4. Organizational culture impact on satisfaction and turnover

Source: Compiled by authors

\section{Conclusion}

The findings of this research show a structural relationship among organizational culture perceived by Pakistani employees and organizational culture. The organizational culture is a bunch of principles in which the organization operates. For the determination of effects of organizational culture on the turnover and job 
satisfaction, culture is an environment of the organization in which employees work. The safe and sound culture almost gives the comfort of employees. The findings and results of this research may be beneficial to administrators of industries who want to reduce employee's turnover. Enhancement of employee's job satisfaction in the workplace might lessen turnover and which helps to certify a stable and competent labor force. Monitoring the working conditions of employees and enhancing the climate of the organization could likely improve the quality of work through helping in retaining qualified workers. The qualified workers and committed labor perform their duties effectively and increase the firm productivity. The implication of this study is beneficial for management to understand the employees' diversity and provide a unique environment for the workers.

\section{Limitation and Future Studies}

Despite the usefulness of this study, the research has its limitations. First and most significantly, the study can be strengthened by increasing the sample size and including participants from other districts other than Muzaffargarh, Layyah, and DG. Khan in Pakistan. Second, the current study was limited to Pakistan. For results comparison, subsequent researches should contemplate replicating this study in other developing countries in Asia and beyond. Finally, the present study did not examine all other factors related to organizational culture, employee welfare and performance. Future studies should focus on other antecedents of organizational culture or outcomes such as organizational citizenship behavior, organizational commitment and employees' intention to stay at work. All in all, these suggested future avenues of study stand to immensely contribute new knowledge to the existing body of organizational culture and employee turnover literature in Pakistan - a context that is often most neglected by some researchers in developing countries.

\section{References}

1. Alvesson, M. (2005). Understanding Organizational Culture, ( $3^{\text {rd }}$ edition). London, Sage Publication. Available at: https://epdf.pub/understanding-organizational-culture.html.

2. Beechler, S.,Woodward, I. C. (2009). The global "war for talent". Journal of International Management, 15, 273-285. https://doi.org/10.1016/j.intman.2009.01.002.

3. Bhati, A., Manimala, M. J. (2011). Talent acquisition and retention in social enterprises. Journal of Security and Sustainability Issues, 1(1), 37-51. http://dx.doi.org/10.9770/jssi.2011.1.1(4.)

4. Buhai, S., Cottini, E., Nielseny, N. (2008). The impact of Workplace Conditions on Firm Performance. Working Paper Number, 23, 08-13. http://dx.doi.org/10.2139/ssrn.1262698.

5. Cameron, K. S., Quinn, R. E. (2006). Diagnosing and changing organisational culture base on the competing values framework. San Francisco, Jossey-Bass. Available at: https://www.academia.edu/19681050/Diagnosing_and_Changing_Organizational_Culture.

6. Castillo, J. X., Cano, J. (2004). Factors Explaining Job Satisfaction Among Faculty. Journal of Agricultural Education, 45(3), 65-74. Available at: https://pdfs.semanticscholar.org/3c79/d16c56f99a7a730eb7fa53d5c3d6134fa785.pdf.

7. Deal, T. E., Kennedy, A. A. (2002). Corporate Cultures. Reading, M A; Addison. Wesley. Available at: https://pdfs.semanticscholar.org/62a7/56d3f389bb331913dc8169b5ef98699e7df0.pdf.

8. Denison, D. R, Haaland, S., Goelzer, P. (2004). Corporate culture and organizational effectiveness, Is Asia different from the rest of the world. Organisational Dynamics, 33(1), 98-109. doi:10.1016/j.orgdyn.2003.11.008.

9. Fey, C.F., Denison, D.R. (2003). Organizational culture and effectiveness. Can American theory be applied in Russia. Organisation Science, 14(6), 686-706. Available at: https://deepblue.lib.umich.edu/bitstream/handle/2027.42/39984/wp598.pdf?sequence=3.

10.Harter, J. K., Schmidt, F. L., Hayes, T. L. (2002). Business-unit-level relationship between employee satisfaction, employee engagement, and business outcomes: A meta analysis. Journal of applied pyschology , 87(2), 268. Available at: https://psycnet.apa.org/buy/2002-12397-006.

11.Hartnell, C.A., Ou, A.Y., Kinicki, A. (2011). Organizational culture and organizational effectiveness. A meta-analytic review. Journal of Applied Psychology , 96, 677-692. https://doi.org/10.1037/a0021987.

12.Hartog \& Verburg (2004). High performance work systems, organizational culture and firm effectiveness. Human Resource Management Journal, 14(1), 55-78. https://doi.org/10.1111/j.1748-8583.2004.tb00112.x.

13.Hoppok and Spielgler (1938). Job Satisfaction Occupations. The Vocational Guidance Journal, 16(7), 636643. https://doi.org/10.1002/j.2164-5892.1938.tb00348.x.

14.Huang, M., Li, P., Meschke, F., \& Guthrie, J. P (2015). Family firms, employee satisfaction, and corporate performance. Journal of corporate finance, 34, 108-127. https://doi.org/10.1016/j.jcorpfin.2015.08.002. 
15.Meterko, M., Mohr, D.C., Young, G.J. (2004). Teamwork culture and patient satisfaction in hospital. Medical care, 42, 492-8. Available at: https://www.jstor.org/stable/4640779.

16.Mulcahy and Betts (2005). Transforming culture: an exploration of unit culture and nursing retention within a neonatal unit. Journal of Nursing Management , 13(6), 519-23. https://doi.org/10.1111/j.13652934.2005.00588.x.

17. Ogbonna \& Harris (2008). Leadership style, organizational culture and performance. Empirical evidence from UK Companies. International Journal of Human Resource Management, 766-788. https://doi.org/10.1080/09585190050075114.

18.Raziqa and Maulabakhsha (2014). Impact of Working Environment on Job Satisfaction. Procedia Economics and Finance, 23(Part of special issue: Global Conference on Business, Economics, Management and Tourism), 717-725. https://doi.org/10.1016/S2212-5671(15)00524-9.

19.Schein, E. H. (2011). The Corporate Culture Survival Guide, Sense and Nonsense about Cultural Change. San Francisco, Jossey-Bass Publishers. Available at: https://dspace.mit.edu/bitstream/handle/1721.1/2759/SWP-4091-43770202.pdf.

20.Symitsi, Stamolampros \& Daskalakis (2018). Employees' online reviews and equity prices. Economics Letters, 162, 53-55. https://doi.org/10.1016/j.econlet.2017.10.027.

21.Vroom, V. (1964). Work and Motivation. Jhon Wiley and Sons, 91. Available at: https://psycnet.apa.org/record/1964-35027-000.

22.Wahl \& Prause (2013). Toward understanding resources, competences, and capabilities: business model generation approach. Entrepreneurship and Sustainability Issues, 2(1), 67-80. DOI: 10.9770/jesi.2013.1.2(1). 